\title{
Pyrolysis and combustion of sugarcane bagasse
}

\author{
L. C. Morais $^{1}$ - A. A. D. Maia ${ }^{1}$ - M. E. G. Guandique ${ }^{1} \cdot$ A. H. Rosa ${ }^{1}$
}

Received: 19 July 2016/Accepted: 18 March 2017/Published online: 3 April 2017

(C) Akadémiai Kiadó, Budapest, Hungary 2017

\begin{abstract}
The inadequate and indiscriminate disposal of sugarcane bagasse (SCB) has received much attention. The exploration of bioenergy properties of biomasses and its biochars play an important role in achieving their utilization. In this context, understanding thermal conversion processes of biomass and biochars it is crucial to use them at bioenergy production. The aim of this study was to investigate thermal behavior of SCB biomass residue, as well as his biochar, by thermogravimetric analysis (TG), including thermodynamic parameters for non-isothermal analyses using Ozawa-Flynn-Wall (OFW), KissingerAkahira-Sunose (KAS) and Friedman, kinetic isoconversional methods. Thermal analyses were conducted under oxidative and inert atmosphere at heating rates of 5, 7.5 and $10{ }^{\circ} \mathrm{C} \mathrm{min}^{-1}$. The hemicellulose maximum mass loss rate was at $250{ }^{\circ} \mathrm{C}$, cellulose at $330{ }^{\circ} \mathrm{C}$ and lignin decomposition from 190 to $500{ }^{\circ} \mathrm{C}$, but the maximum mass loss rate at $430{ }^{\circ} \mathrm{C}$, the devolatilization was at $\sim 200{ }^{\circ} \mathrm{C}$. The variation of apparent $E_{\alpha}$ represents single-step kinetics on the degradation process and OFW model is in better accordance with the experimental data and satisfactorily described the complexity of degradation process. SEM/ EDX analyses showed carbon, oxygen, aluminum, magnesium and iron.
\end{abstract}

Keywords Sugarcane bagasse - Bioenergy - Thermal analysis $\cdot$ SEM/EDX

L. C. Morais

leandro@sorocaba.unesp.br

1 Institute of Science and Technology, São Paulo State University (UNESP) "Júlio de Mesquita Filho", Av. Três de Março, 511, Alto da Boa Vista, Sorocaba, São Paulo 18087-180, Brazil

\section{Introduction}

Cellulose, the major constituent of all plant materials, forms about half to one-third of plant tissues and is constantly replenished by photosynthesis. Thus, it is the most abundant and renewable natural resource on Earth [1]. Sugar factories generate approximately $300 \mathrm{~kg}$ of bagasse (50\% moisture) per metric ton of sugarcane, being the major by-product of the sugar cane industry, very promising raw material and the most important agricultural residues in terms of availability and potential for use as a bioenergy resource [2]. About 50\% of this amount produced is enough to supply of energy [3, 4].

Sugarcane bagasse is the residue produced by mills after juice extraction, and at 1990s, sugarcane trash in Brazil was burned in before the harvest to make cutting the cane and manual harvesting easier [5]. Bagasse and sugarcane straw are lignocellulosic materials that have attracted interest from scientists as potential sources of waste reuse $[6,7]$.

For a better understanding, several researchers investigated thermal decomposition of biomass by thermogravimetric analysis (TG) and have attracted considerable attention [8,9]. Pyrolysis processes have been improved and are now widely used to biochar production. Biomass pyrolysis is a complex process due to differences in the chemical composition of components within the biomass material [10]. Therefore, the thermal behavior of sugarcane bagasse must be thoroughly studied.

For this reason, the use of techniques to characterize surfaces of biomass such as scanning electron microscopy (SEM) and energy-dispersive X-ray spectrometry (EDX) provides a more direct form of establishing the chemical and morphological changes occurring on the surface. Scanning electron microscopy is a technique widely used 
to determine physical nature of solid surfaces. The provided images give a detailed surface view and a general sight of the sample, being the most common tool used to observe micro-structural transformations that occur during thermal degradation of the biomass.

The aim of this study was to explore their thermal behavior and better understanding pyrolysis process of SCB by thermogravimetric analysis (TG), including thermodynamic parameters for non-isothermal analyses using Ozawa-Flynn-Wall (OFW), Kissinger-Akahira-Sunose (KAS) and Friedman kinetic isoconversional methods i.e., apparent activation energy $\left(E_{\alpha}\right)$ and pre-exponential factor $(A)$ in order to utilize the sugarcane bagasse as biomass for energy applications.

\section{Methods}

\section{Samples preparation}

The sugarcane bagasse used on this study was obtained from Cerquilho City. At the laboratory, the biomass was washed in tap water and dried by oven drying Solab model SL-100/42 at $105{ }^{\circ} \mathrm{C}$ to constant mass [12]. After drying, the samples were ground in a Wiley mill, MA048-Marconi, followed by sieving, Solotest sieve, NBR \# 100 (0.149 mm).

\section{Thermal analysis}

Thermogravimetric analysis was carried out utilizing heating rates of $5,7.5$ and $10{ }^{\circ} \mathrm{C} \mathrm{min}{ }^{-1}$ in simultaneous DSC-TGA equipment, TA Instruments, model SDT Q600, from 25 to $800{ }^{\circ} \mathrm{C}$. Air and nitrogen were used as purge gas at a $120 \mathrm{~mL} \mathrm{~min}{ }^{-1}$ flow rate. About $1.5 \mathrm{mg}$ of the biomass was used in alumina pans in each analysis. The TA Instruments software provides the thermogravimetry (TG) and derivative thermogravimetry (DTG) curves.

\section{Biochar estimation}

Runs were performed in oxidative and inert atmosphere. To estimate the biochar formation, it was considered that at a given temperature " $T$," the SCB analyzed in oxidative atmosphere loses the residual water and other products arising from the decomposition of inorganic materials, the decomposition and burnout of organic matter is complete, and only the inorganic oxides remain in the residual mass at the end of the thermal analysis.

The SCB analyzed in inert atmosphere loses the same products as the previous case for the inorganic contents, but the organics are pyrolyzed this time, forming biochar as residual carbonaceous matter. The biochar formed at a given temperature " $T$ " is estimated by the difference of respective residual masses in oxidative and inert atmosphere at " $T$ " and heating rate of $5{ }^{\circ} \mathrm{C} \mathrm{min}^{-1}$.

\section{Kinetic study}

Biomass pyrolysis is a complex process, due to differences in the chemical composition of his components. Usually, mass loss rate curves contain overlapping peaks and mathematical models are typically used for their understanding [13].

Quantifying the rate of a chemical reaction is of high importance during the degradation of its main components. Thermo-kinetic behavior of the biomass allows control the reaction rate as a function of temperature, pressure and composition [14].

Isoconversional methodology in non-isothermal experiments is recommended from International Confederation for Thermal Analysis and Calorimetry-ICTAC kinetics committee [15].

Model-free methods are based on an isoconversional method where the activation energy is a function of the conversion degree of a chemical reaction [16]. An extensive comparison study between different methods that model-free and multi-heating rate methods is particularly successful in describing the multi-step kinetic processes. In this work, we have combined three kinds of model-free kinetics to understand the pyrolytic kinetic behavior of sugarcane bagasse. The one-step global model assumes that the degradation processes result in a single reaction, below [17].

Biomass $\stackrel{k}{\longrightarrow}$ Volatiles + Biochar

where $k$ is the rate constant of reaction whose temperature dependence is expressed by the following Arrhenius equation:

$k=A \mathrm{e}^{\left(-\mathrm{E}_{\mathrm{a}} / \mathrm{RT}\right)}$

where $E_{\mathrm{a}}$ apparent activation energy $\left(\mathrm{kJ} \mathrm{mol}^{-1}\right) ; T$ is the absolute temperature $(K) ; \quad R$ universal gas constant $8.31 \mathrm{~J} \mathrm{~K}^{-1} \mathrm{~mol}^{-1} ; A$ is the pre-exponential factor $\left(\mathrm{s}^{-1}\right)$.

The rate of transformation from solid state to volatile product is described by the following expression [18]

$\frac{d_{\alpha}}{d_{\mathrm{t}}}=k(T) f(\alpha)$

where $\alpha$ is conversion degree of the process; $k(t)$ is the time of process; $f(\alpha)$ is the rate constant and the reaction model.

Conversion degree, $\alpha$, represents the normalized form of mass loss data of decomposed sample and is defined as below [19] 
$\alpha=\frac{m_{\mathrm{i}}-m_{\alpha}}{m_{\mathrm{i}}-m_{\mathrm{f}}}$

where $m_{\mathrm{i}}$ is the initial mass of the sample; $m_{\alpha}$ is the actual mass; $m_{\mathrm{f}}$ is the mass after combustion.

Combining Eqs. (1) and (2) gives the fundamental expression (4) of analytical methods to calculate kinetic parameters, on the basis of TG results.

$\frac{d_{\alpha}}{d_{\mathrm{t}}}=A f(\alpha) \mathrm{e}^{-\mathrm{E}_{\alpha} / \mathrm{RT}}$

The expression of the function $f(\alpha)$ and its derivative $f$ (a) are used for describing solid-state first-order reaction:

$f(\alpha)=(1-\alpha)^{\mathrm{n}}$

where $n$ is the order reaction.

Substituting expression (5) into Eq. (4) gives the expression of reaction rate in the form:

$\frac{d_{\alpha}}{d_{\mathrm{t}}}=A(1-\alpha)^{\mathrm{n}} \mathrm{e}^{-\mathrm{E}_{\alpha} / \mathrm{RT}}$

For non-isothermal TG/DTG experiments at linear heating rate $\beta=\mathrm{d} T / \mathrm{d} t$, Eq. (6) can be written as:

$\frac{d_{\alpha}}{d_{\mathrm{t}}}=\frac{A}{\beta}(1-\alpha)^{\mathrm{n}} \mathrm{e}^{-\mathrm{E}_{\alpha} / \mathrm{RT}}$

This equation expresses the fraction of material consumed in the time.

Kinetic study in this work was calculated considering only sugarcane bagasse biomass dehydrated using Friedman, Kissinger-Akahira-Sunose and Ozawa-Flynn-Wall methods described below.

\section{Friedman}

Friedman's method applies the logarithm of conversion rate as a function of the reciprocal temperature at different degrees of conversion. Using Eqs. (1) and (2), the equation proposed by [20] that allows the activation energy $E$ to be determined for each given conversion degree, can be expressed as:

$\ln \left(\beta \frac{d_{(\mathrm{a})}}{\mathrm{d} T}\right)=\ln \left(\frac{d_{(\mathrm{a})}}{\mathrm{d} t}\right)=\ln [A f(a)]-\frac{E_{\mathrm{a}}}{R T}$

where $i$ denotes the ordinal number of a non-isothermal experiment conduced at the heating rate $\beta_{\mathrm{i}}$ and the subscript $\alpha$ denotes the quantities evaluated at a specific conversion degree $\alpha$.

By rearranging and integrating Eq. (8):

$\ln \left(\frac{d_{\alpha}}{d_{\mathrm{t}}}\right)_{\mathrm{a}, \mathrm{i}}=\ln \left[A_{\mathrm{a}} f(\alpha)\right]-\frac{E_{\mathrm{a}}}{R T_{\mathrm{a}, \mathrm{i}}}$

The value of $d_{\alpha} / d_{\mathrm{t}}$ is obtained numerically using $\Delta \alpha=0.025$ and linear interpolation of the experimental data. The plot of $\ln \left(\beta d_{\alpha} / d_{\mathrm{t}}\right)$ versus $1 / T$ at constant $\alpha$ for a set of $\beta$ values gives a family of straight line with slope $-E_{\alpha} / R$. This model can be applied to the data sets obtained at different heating rates $\beta$ and different temperatures.

\section{Kissinger-Akahira-Sunose}

Kissinger-Akahira-Sunose method is assumed to be one of the best isoconversional methods [21] applied without any assumption concerning the kinetic model [16].

$\ln \left(\frac{\beta}{T^{2}}\right)=\ln \left(\frac{A E_{\mathrm{a}}}{g(\alpha) R}\right)-\frac{E_{\mathrm{a}}}{R T}$

where $E_{\mathrm{a}}$ and $A$ are, respectively, the apparent activation energy and the pre-exponential factor at a given conversion degree, $\alpha$, and the temperature $T$ is that which the conversion $\alpha$ is reached at a heating rate $\beta$. The plot of $\ln \left(\beta / T^{2}\right)$ versus $1 / T$ slope gives $-E_{\mathrm{a}} / R[16]$.

\section{Ozawa-Flynn-Wall}

OFW method is one of the most common and widely accepted methods in scientific community to compute thermo-kinetic parameters from experimental data [13]. An isoconversional integral method seems to be a safer alternative for the calculation of meaningful activation energy values [22]. The Ozawa-Flynn-Wall kinetics isoconversional method was applied considering the equation below [23]

$\ln (\beta)=C_{\alpha}-\frac{E_{\mathrm{a}}}{R T}$

where $\beta$ is $b$ heating rate; $E_{\mathrm{a}}$ apparent activation energy; $C_{\alpha}$ function of the conversion degree $\alpha ; R$ universal gas constant $8.31 \mathrm{~J} \mathrm{~K}^{-1} \mathrm{~mol}^{-1} ; T$ the absolute temperature $(\mathrm{K})$.

The kinetic study requires at least three different values of heating hate $(\beta)$ and used the same values of alpha in different absolute temperatures $(T)$ obtained at thermogravimetric curves. This methodology allows investigating whether the mechanism of the conversion is charging with the conversion degree estimating the respective $E_{\alpha}$ at a specific conversion degree $(\alpha)$.

\section{Thermodynamic parameter}

Pre-exponential factor $(A)$ represents the frequency of collisions between reactant molecules. It was calculated based on Arrhenius equation for each conversion degree $[23,24]$. This parameter was calculated using an intermediate value of $\beta$ (i.e., $7.5^{\circ} \mathrm{C} \mathrm{min}^{-1}$ ) and the equation:

$A=\beta E_{\mathrm{a}} \exp \left(\frac{E_{\mathrm{a}} / R T m}{R T m^{2}}\right)$ 


\section{SEM and EDX analyses}

The sample of sugarcane bagasse biomass before and after pyrolysis process was examined by SEM for surface analysis (JEOL JSM-6010LA). The surface elemental analysis of sugarcane bagasse biomass was also carried out by energy-dispersive X-ray spectroscopy. Samples without metal caps were placed on a carbon tape and observed applying a potential of $3 \mathrm{kV}$ and $500 \times / 1000 \times$ amplified. SEM and EDX analyses were realized considering sugarcane bagasse biomass dehydrated and his biochar passed through pyrolysis process in a muffle furnace (Quimis Q318S21) at temperature of $350{ }^{\circ} \mathrm{C}$ in three different conditions of heating rates, 0,30 and $60 \mathrm{~min}$ in almost total absence of oxygen.

\section{Results and discussion}

\section{Thermal analysis}

From thermogravimetric results, it was observed that biomass decomposition involved three main stages as the water evaporation; devolatilization of thermally labile and more stable volatiles; and biochar formation.

At the thermal degradation of biomass can be possible to see three-step mass losses as moisture evaporation, oxidative degradation and combustion of biochar (Fig. 1). These stages of combustion do not occur uniformly or sequentially but are related to nonlinear chemical and thermal processes.

Sugarcane bagasse is basically formed about 39, 28 and $18 \%$ of cellulose, hemicellulose and lignin, respectively, and this is the most important characteristics of this biomass. The thermal degradation of biomass also depends on the mass ratio of its main components, as hemicellulose, cellulose and lignin. The temperature range of hemicellulose decomposition is from 190 to $300{ }^{\circ} \mathrm{C}$, with maximum mass loss rate at $250{ }^{\circ} \mathrm{C}$. Cellulose decomposes within the temperature range from 250 to $350{ }^{\circ} \mathrm{C}$, with maximum mass loss rate at $330{ }^{\circ} \mathrm{C}$. The temperature range of lignin decomposition in comparison with that of hemicellulose and cellulose is broader, from 190 to $500{ }^{\circ} \mathrm{C}$, but the maximum mass loss rate at $430{ }^{\circ} \mathrm{C}$, the devolatilization was at $\sim 200{ }^{\circ} \mathrm{C}$.

Nevertheless, the maximums of cellulose and lignin decomposition are almost overlapping and the thermal decomposition of sugar cane bagasse is given by the superposition of hemicellulose, cellulose and lignin decomposition. It was observed from TG and DTG curves shown in Fig. 1 that 10.2, 9.14 and 8.47 mass\% mass losses occurred between temperatures of 25 and $105^{\circ} \mathrm{C}$.

In Fig. 1d, e, f, was observed mass loss of 8.4, 8.7 and 7.4 mass $\%$ at $5,7.5$ and $10{ }^{\circ} \mathrm{C} \min ^{-1}$, respectively. This mass loss is associated with water evaporation, and then, a slight mass loss took place which could be due to the loss of volatiles. Thermal decomposition and degradation for biomass samples in air and nitrogen atmosphere initiated at corresponding anticipated temperatures of $236,210{ }^{\circ} \mathrm{C}$, and these variations in initial degradation temperatures of biomass have been related to the differences in the elemental and chemical compositions of the samples and degradation or decomposition processes. Total mass loss due to total degradation was higher in those samples which have higher volatile matter and lower ash content.

Analyzing the TG and DTG distributions of SCB at three different heating rates, it is possible to see that the DTG curves have one main peak accompanied by a shoulder and this behavior can be explained by the higher volatile matter and holocellulose contents and the overlapping of these materials. In both atmospheres, it is possible to observe that the lower heating rate, lower is the temperature at which they occur. Also, the difference between the process at the three heating rates investigated it is not significant. (a)

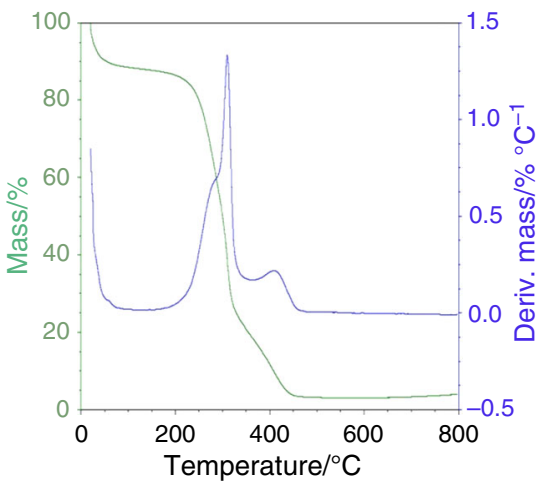

(b)

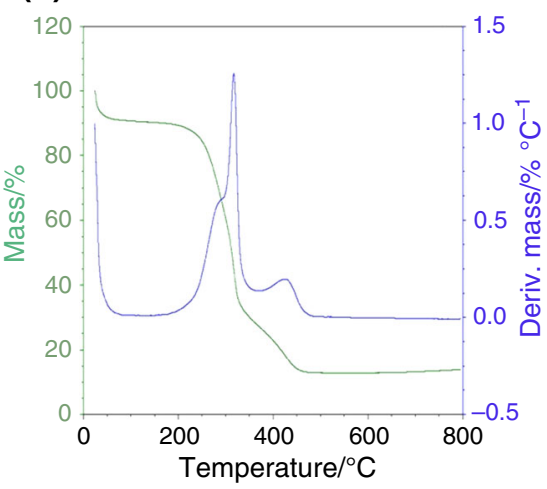

(c)

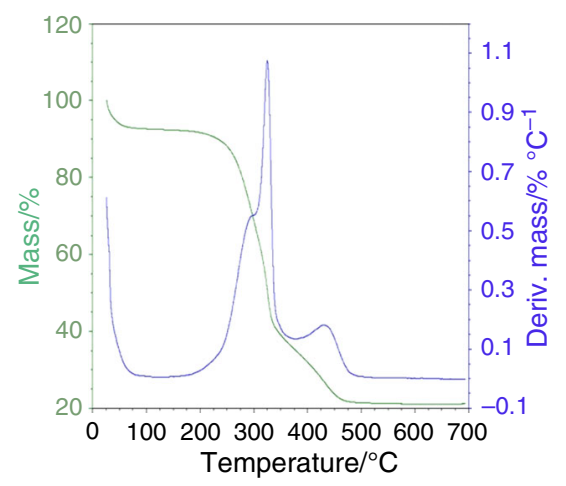

Fig. 1 TG and DTG curves of SCB at three different heating rates a 5, b 7.5 and $\mathbf{c} 10{ }^{\circ} \mathrm{C} \mathrm{min}{ }^{-1}$ and oxidative atmosphere 
Sugarcane bagasse is a herbaceous biomass materials and because of that, the first stage of conversion in the temperature range between 80 and $200{ }^{\circ} \mathrm{C}$ is associated with thermal degradation of the biopolymers (i.e., cellulose) and the second stage $\left(201-400{ }^{\circ} \mathrm{C}\right)$ can be associated with degradation of the carbonaceous matter formed in the first stage.

\section{Biochar estimation}

The pore structure of biochar was affected by the distribution and evolution of organic phases during pyrolysis process. Therefore, change the organic phases of the biomass resulting in a carbon-rich product at lower temperatures its interesting because higher temperatures require expensive and longer production. That low holding temperatures $\left(<500{ }^{\circ} \mathrm{C}\right)$ and short heating times $(<2 \mathrm{~h})$ are generally enough for biochar production.

The TG curves in nitrogen and air atmosphere shown in Fig. 2 allow to observe that the biochar formation occurs mainly between 250 and $500{ }^{\circ} \mathrm{C}$ and from 500 to $800{ }^{\circ} \mathrm{C}$ occurs thermal decomposition of the biomass and others components. Table 1 shows that the highest biochar formation occurs at $450{ }^{\circ} \mathrm{C}$. However, at $450{ }^{\circ} \mathrm{C}$ during $1 \mathrm{~h}$, there is no biochar formation and can be also observed higher quantities of ashes at this condition.

\section{Kinetic study}

The results obtained from thermogravimetric analysis were elaborated according to model-free methods to calculate the kinetic parameter as apparent activation energy and pre-exponential factors. These kinetic parameters were obtained using KAS, Friedman and OFW methods. The situation is particularly complicated, because the thermal degradation of the sugarcane bagasse is a complex process,

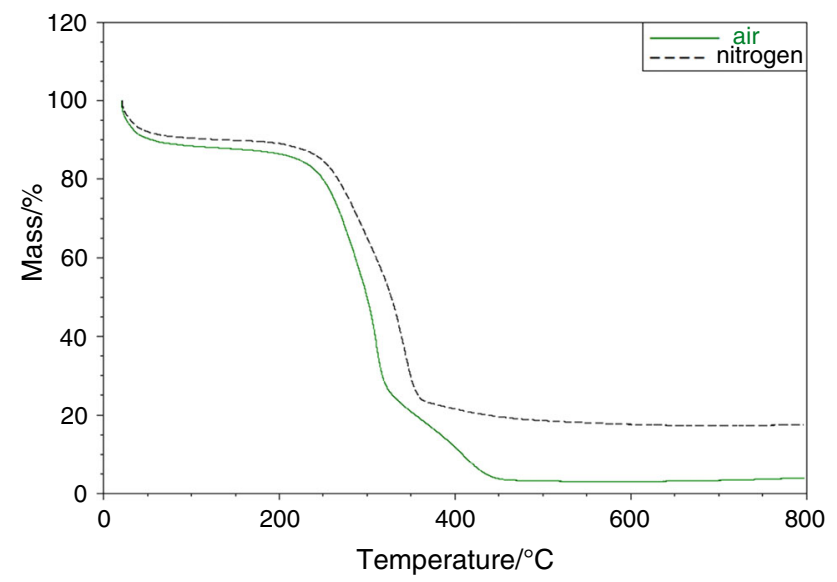

Fig. 2 Thermogravimetric curves of SCB at inert and oxidative atmosphere representing biochar formation where a number of consecutive and parallel reactions are involved.

Figure 3 shows TG and DTG curves of SCB in inert atmosphere. The values used at calculation of these apparent activation energy and pre-exponential factors were obtained from them. The apparent activation energy and pre-exponential factors for SCB are presented in the range $\alpha 30$ and $95 \%$ and the results obtained from Friedman were between 8.17 and $272.78 \mathrm{~kJ} \mathrm{~mol}^{-1}$ and $3.82 \mathrm{E}+01$ and $1.28 \mathrm{E}+03 \mathrm{~s}^{-1}$ for apparent activation energy and pre-exponential factor, respectively. The results obtained from KAS method were between 3.39 and $78.28 \mathrm{~kJ} \mathrm{~mol}^{-1}$ and $1.01 \mathrm{E}+02$ and $3.67 \mathrm{E}+02 \mathrm{~s}^{-1}$ for apparent activation energy and pre-exponential factor, respectively. The results obtained from OFW methods were between 11.04 and $88.56 \mathrm{~kJ} \mathrm{~mol}^{-1}$ and $5.16 \mathrm{E}+01$ and $4.14 \mathrm{E}+02 \mathrm{~s}^{-1}$ for apparent activation energy and preexponential factor, respectively. All the results are given in Table 2.

In lignocellulosic biomass, the apparent activation energy can vary from 80 to $200 \mathrm{~kJ} \mathrm{~mol}^{-1}$ to hemicellulose, $195-286 \mathrm{~kJ} \mathrm{~mol}^{-1}$ to cellulose and $18-65 \mathrm{~kJ} \mathrm{~mol}^{-1}$ to lignin. The apparent activation energies of red pepper varied from 29.49 to $147.25 \mathrm{~kJ} \mathrm{~mol}^{-1}$ [22] similar to the values found for SCB in this work [22, 25]. Values of apparent activation energy between 60 and $120 \mathrm{~kJ} \mathrm{~mol}^{-1}$ are considerate low and can indicate that higher values are required to decompose lignocellulosic biomass.

The overlapping of decomposition reactions of different waste components as well as the interaction among components and derived products gives an apparent reaction rate characterized by an apparent activation energy that describes the decomposition of the waste.

The activation energy estimated with these methods varied from 3.39 to $272.78 \mathrm{~kJ} \mathrm{~mol}^{-1}$. This is due to different components of the waste and their different decomposition mechanisms. This variation denotes changes in reactivity as a result of extent of reaction and the complex nature of the reactions. Most of the variation occurs in the first stages of decomposition ( $\alpha 30-55 \%)$. At latter stages, decomposition is governed by a lower and almost stable activation energy, because of overlapping of the decomposition reactions.

The knowledge of $E_{\mathrm{a}}$ versus $\alpha$ allows detecting multistep processes and predicting the reaction kinetics behavior over a wide temperature range. Figure 5 represents the three model-free behaviors for SCB experiments. It is possible to note that KAS and OFW methods had a similar behavior while Friedman method presented a much higher values of apparent activation energy. The decomposition of SCB was multi-step reaction mechanism, and this can be noted from the nonlinear relationship of activation energy and the conversion rate. 
Table 1 Biochar estimation by the difference between the residual mass of sugarcane bagasse in inert and oxidative atmosphere at determined temperature

\begin{tabular}{|c|c|c|c|c|c|c|c|c|c|c|}
\hline & $250{ }^{\circ} \mathrm{C}$ & $300{ }^{\circ} \mathrm{C}$ & $350{ }^{\circ} \mathrm{C}$ & $400{ }^{\circ} \mathrm{C}$ & $450{ }^{\circ} \mathrm{C}$ & $500{ }^{\circ} \mathrm{C}$ & $550{ }^{\circ} \mathrm{C}$ & $600{ }^{\circ} \mathrm{C}$ & $650{ }^{\circ} \mathrm{C}$ & $700^{\circ} \mathrm{C}$ \\
\hline SCB residual mass/\% in air & 80.01 & 49.18 & 20.95 & 11.52 & 3.68 & 3.13 & 2.98 & 2.99 & 3.09 & 3.27 \\
\hline $\mathrm{SCB}$ residual mass $/ \%$ in nitrogen & 84.72 & 65.25 & 29.6 & 21.48 & 19.53 & 18.53 & 18.03 & 17.61 & 17.36 & 17.29 \\
\hline Biochar estimation $/ \%$ & 4.71 & 16.07 & 8.65 & 9.96 & 15.85 & 15.4 & 15.05 & 14.62 & 14.27 & 14.02 \\
\hline
\end{tabular}
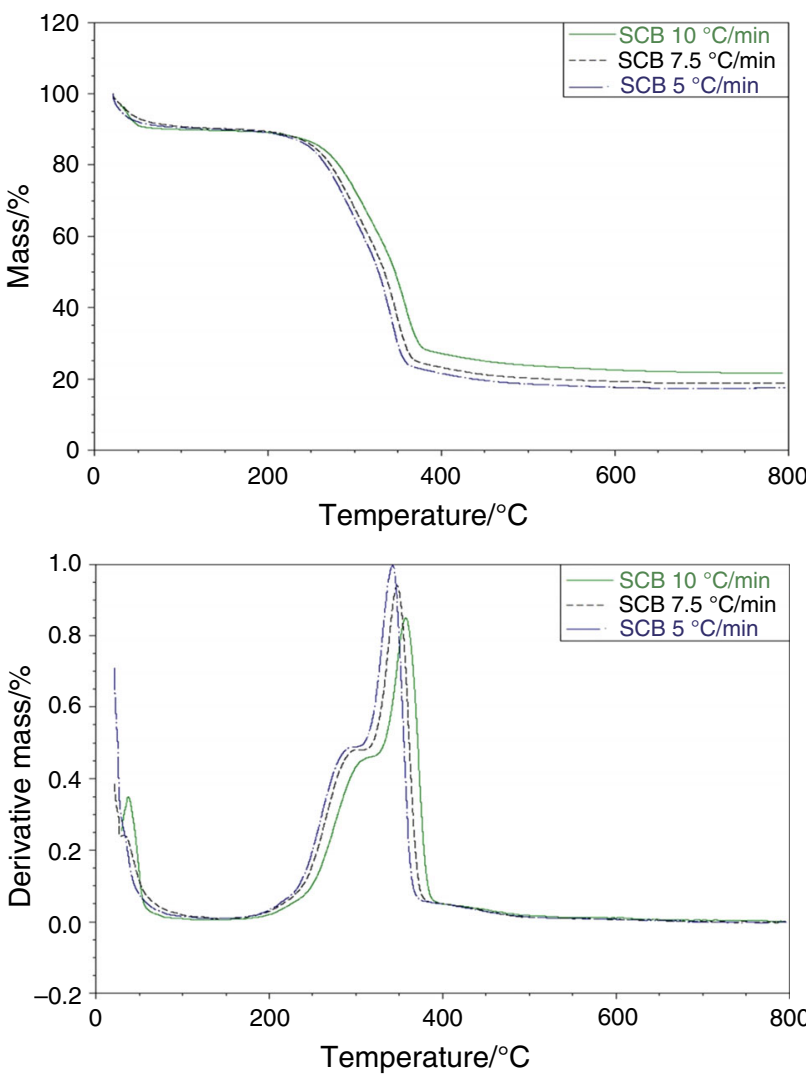

Fig. 3 TG and DTG curves of SCB at three different heating rates in inert atmosphere

These methods are potentially suited for use in systems where many reactions are occurring such that the activation energy varies with time. However, they can fail if the reactions of widely different type occur simultaneously. OFW can be less precise than the Friedman's method.

The results of methods reveal that the apparent activation energy depends on the conversion degree and its values obtained by isoconversional differential and integral methods are different. The systems which have competitive or independent reactions both the Friedman and the OFW methods lead to different values of the activation energy. On the other hand, if $E_{\alpha}$ is independent on $\alpha$, then the two methods lead to practically the same activation energy value. For this reason, a comparison of the results from the two methods was helpful to check on their accuracy.
Figure 4 shows that the activation energy can decrease with the conversion degree which that for the considered range of heating rates $\ln \mathrm{d} \alpha / \mathrm{d} T$ depends linearly on $(1 / T)$.

The values of the apparent activation energy obtained by Friedman methods are higher than those by the OFW and KAS methods. It can be seen from these results that for the largest part of the conversion range, KAS and OFW do not differ significantly both in the case proving the validity and accordance of the models. The major advantage of OFW method is that it does not require any assumptions concerning the form of the kinetic equation other than the Arrhenius-type temperature dependence. However, Friedman method is related to the OFW method inasmuch as they both rely on the use of several different heating rates.

The pre-exponential factors are directly related to the biomasses structures and the values of first-order pre-exponential factors for SCB ranged from $10^{1}$ to $10^{3}$ to Friedman, $10^{1}$ to $10^{2}$ to KAS and OFW. The low preexponential factors $\left(<10^{9} \mathrm{~s}^{-1}\right)$ indicate a surface reaction at SCB, a harder complex and more difficult structure to breakdown. The lower values in $A$ and $E_{\alpha}$ represent a faster and easier decomposition of this biomass for the respective conversion degree.

\section{SEM and EDX study of SCB}

Images obtained by scanning electron microscopy on the surfaces of milled raw bagasse revealed two main morphological features, fiber structures and pith. The fiber surface is formed by parallel stripes and is partially covered with residual material and pith is a more fragile and fragmented structure containing pits, which are small pores connecting neighboring cells on the surface of the walls.

SEM clearly demonstrated that there is more uniformity before pyrolysis process and highly heterogeneous pores present at biochar and number of pore in the biomass was higher than in the initial case. Biomass presents an uneven structure before and after high temperatures exposure. Fiber surfaces were also changed by milling treatment and surface residual pith was removed and the parallel stripes appear more exposed, SCB bundles start to dismantle and the fibers become detached from the others. Bagasse unstructuring is favored by the loss of cohesion between 
Table 2 Kinetic study of SCB using three isoconversional methods at different heating rates

\begin{tabular}{|c|c|c|c|c|c|c|}
\hline \multicolumn{3}{|l|}{ FRIEDMAN } & \multicolumn{2}{|l|}{ KAS } & \multicolumn{2}{|l|}{ OFW } \\
\hline Conversion degree $(\alpha) / \%$ & $E_{\mathrm{a}} / \mathrm{kJ} \mathrm{mol}^{-1}$ & $A / \mathrm{s}^{-1}$ & $E_{\mathrm{a}} / \mathrm{kJ} \mathrm{mol}^{-1}$ & $A / \mathrm{s}^{-1}$ & $E_{\mathrm{a}} / \mathrm{kJ} \mathrm{mol}^{-1}$ & $A / \mathrm{s}^{-1}$ \\
\hline 30 & 46.95 & $2.19 \mathrm{E}+02$ & 21.64 & $1.01 \mathrm{E}+02$ & 32.50 & $1.52 \mathrm{E}+02$ \\
\hline 35 & 275.48 & $1.29 \mathrm{E}+03$ & 67.79 & $3.18 \mathrm{E}+02$ & 78.26 & $3.66 \mathrm{E}+02$ \\
\hline 40 & 272.78 & $1.28 \mathrm{E}+03$ & 74.84 & $3.51 \mathrm{E}+02$ & 85.21 & $3.98 \mathrm{E}+02$ \\
\hline 45 & 184.51 & $8.63 \mathrm{E}+02$ & 78.28 & $3.67 \mathrm{E}+02$ & 88.56 & $4.14 \mathrm{E}+02$ \\
\hline 50 & 188.23 & $8.80 \mathrm{E}+02$ & 75.00 & $3.51 \mathrm{E}+02$ & 85.18 & $3.98 \mathrm{E}+02$ \\
\hline 55 & 204.84 & $9.58 \mathrm{E}+02$ & 71.28 & $3.34 \mathrm{E}+02$ & 81.33 & $3.80 \mathrm{E}+02$ \\
\hline 60 & 142.83 & $6.68 \mathrm{E}+02$ & 59.80 & $2.80 \mathrm{E}+02$ & 69.68 & $3.26 \mathrm{E}+02$ \\
\hline 65 & 71.51 & $3.34 \mathrm{E}+02$ & 57.78 & $2.71 \mathrm{E}+02$ & 67.51 & $3.16 \mathrm{E}+02$ \\
\hline 70 & 50.33 & $2.35 \mathrm{E}+02$ & 57.21 & $2.68 \mathrm{E}+02$ & 66.77 & $3.12 \mathrm{E}+02$ \\
\hline 75 & 65.37 & $3.06 \mathrm{E}+02$ & 53.74 & $2.52 \mathrm{E}+02$ & 63.12 & $2.95 \mathrm{E}+02$ \\
\hline 80 & 77.04 & $3.60 \mathrm{E}+02$ & 47.22 & $2.21 \mathrm{E}+02$ & 56.40 & $2.64 \mathrm{E}+02$ \\
\hline 85 & 57.87 & $2.71 \mathrm{E}+02$ & 36.23 & $1.70 \mathrm{E}+02$ & 45.12 & $2.11 \mathrm{E}+02$ \\
\hline 90 & 8.17 & $3.82 \mathrm{E}+01$ & 3.39 & $1.58 \mathrm{E}+01$ & 11.04 & $5.16 \mathrm{E}+01$ \\
\hline 95 & 58.23 & $2.72 \mathrm{E}+02$ & 28.17 & $1.32 \mathrm{E}+02$ & 33.36 & $1.56 \mathrm{E}+02$ \\
\hline
\end{tabular}

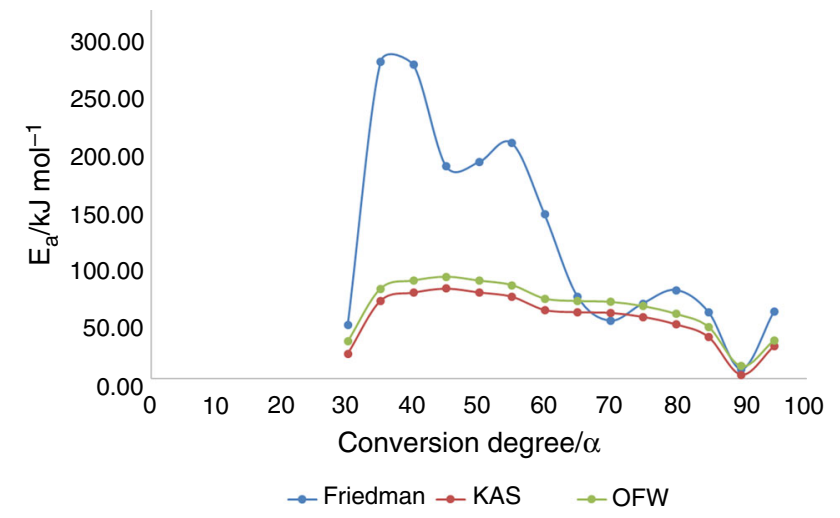

Fig. 4 Apparent activation energy varying according to different methods and conversion degree

neighboring cell walls, as well as by changes in the inner cell wall structure, such as damaging, hole formation and loss of mechanical resistance it is occur as a consequence of lignin removal from the sample. Figure 5 shows general view of fibers and pith of SCB dehydrated and underwent knife milling and $1000 \times$ amplified. The diameter of SCB biomass fiber was much bigger, and each fiber appears to be composed of several microfibrils. Each elementary fiber possesses a compact structure; exhibiting an alignment in the fiber axis direction. The micrograph of the original sugarcane bagasse also displays lot of non-fibrous components scattered over the fiber surface.

During thermal conversion, large amounts of volatile matter flow from the solid material in a short time that varies the particles surface, shrinking and splitting it.

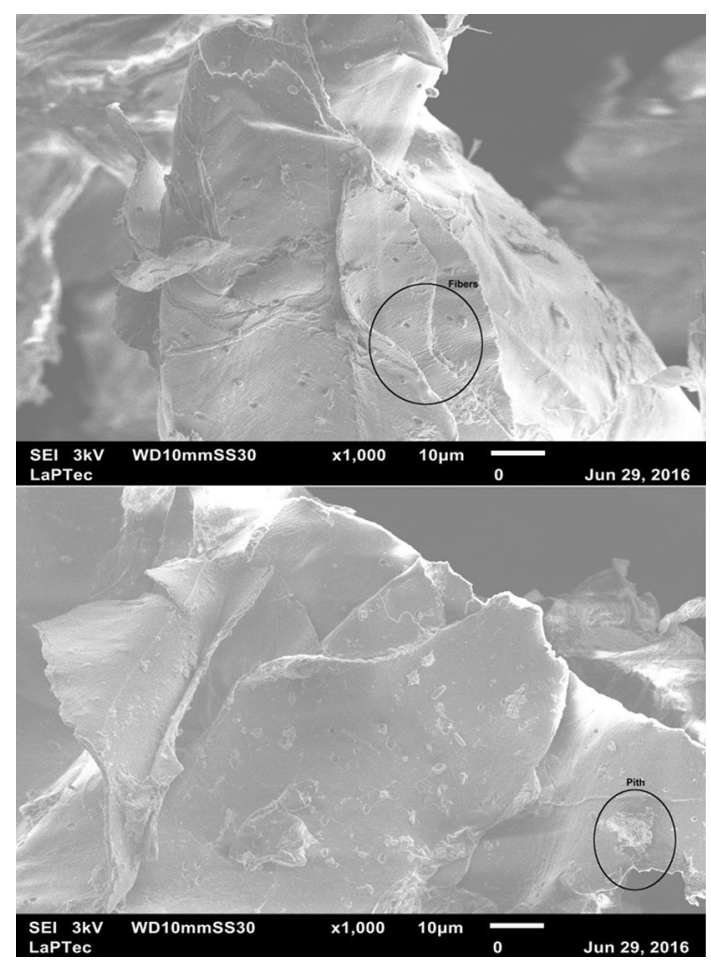

Fig. 5 General view of surface of SCB obtained by scanning electron microscopy

Therefore, there is a big morphological difference among the four phases. SCB ground samples the fibrous structure, with long fibers, according to its vegetable origin can be determined. Harder structures as biochar present spherical shape as coming from a previous pyrolysis present a much 
thinner distribution after grinding. After pyrolysis processes, every sample presents a homogenous structure probably because of agglomeration phenomenon due to melting of alkali compounds.

Figure 6 shows general view of sugarcane bagasse pyrolyzed at $350{ }^{\circ} \mathrm{C}$ and three different heating rates, $(\mathrm{a}, \mathrm{b})$ heating rate of $0 \mathrm{~min},(\mathrm{c}, \mathrm{d})$ heating rate of $30 \mathrm{~min}$ and (e, f) heating rate of $60 \mathrm{~min}$. Samples were amplified in 500 and $1000 \times$, respectively.

The fibers presented circular cross-sectional shapes. Lignin was partially removed by thermal conversion process, and the morphology of pyrolyzed bagasse was different in respect of sugarcane bagasse biomass. The SCB biomass has smooth and continuous surface, whereas the SCB pyrolyzed has a rough surface. Thermal conversion process showed a porous structure. This indicates that pyrolysis removed external fibers which increases surface area allowing cellulose becomes more accessible to be degradeted. Cellulose is present as long chain polymers packed into microfibrils covered by hemicellulose and lignin. The morphology of biochar showed a defibrillation and reduction on fiber length when pyrolysis temperatures were increased. As can be determined after exposure to this high temperature, the composition has again changed, remaining the hardest carbon (70\%), oxygen $(24 \%)$ and silicon (3\%) structure remains as an important element in ashes composition, while most of the impurity precursors are still there in low quantities, near $1 \%$ of the whole mass for aluminum, magnesium and iron (Fig. 7).

An important possibility given by this analysis consists of the identification of impurity particles generating alkalis in ashes, considering them as oxides, hydroxides and carbonates. Figure 5 presents EDX elements.
Fig. 6 Surface images of sugarcane bagasse biochar pyrolyzed at $350{ }^{\circ} \mathrm{C}$, a, b general view of the sample pyrolyzed at $350{ }^{\circ} \mathrm{C}$ during 0 min; c, $\mathbf{d}$ sample pyrolyzed at $350{ }^{\circ} \mathrm{C}$ during $30 \mathrm{~min}$; e, f sample pyrolyzed at $350{ }^{\circ} \mathrm{C}$ during $60 \mathrm{~min}$. Samples were amplified at 500 and $1000 \times$, respectively

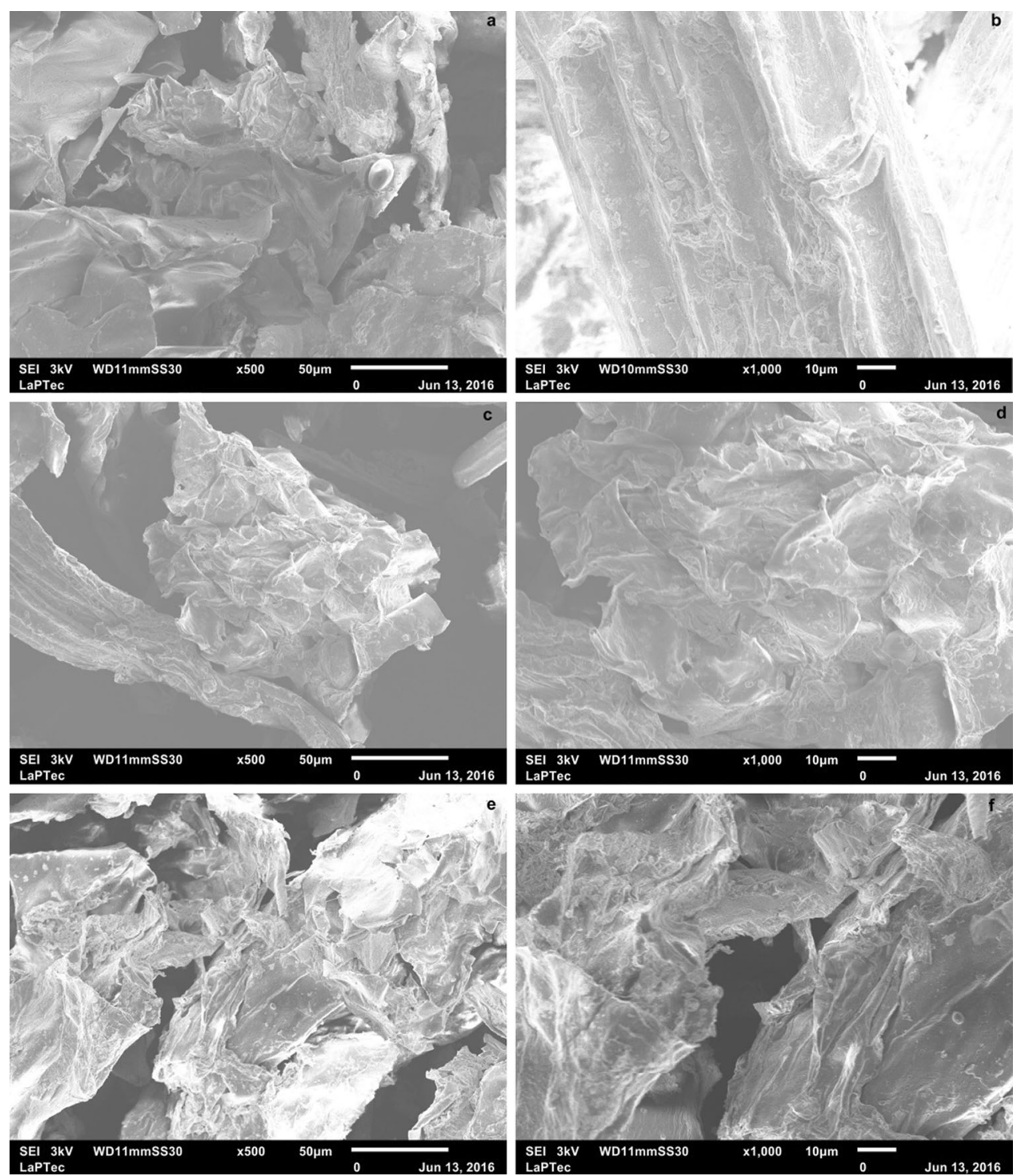


Fig. 7 EDX analyses of sugarcane bagasse

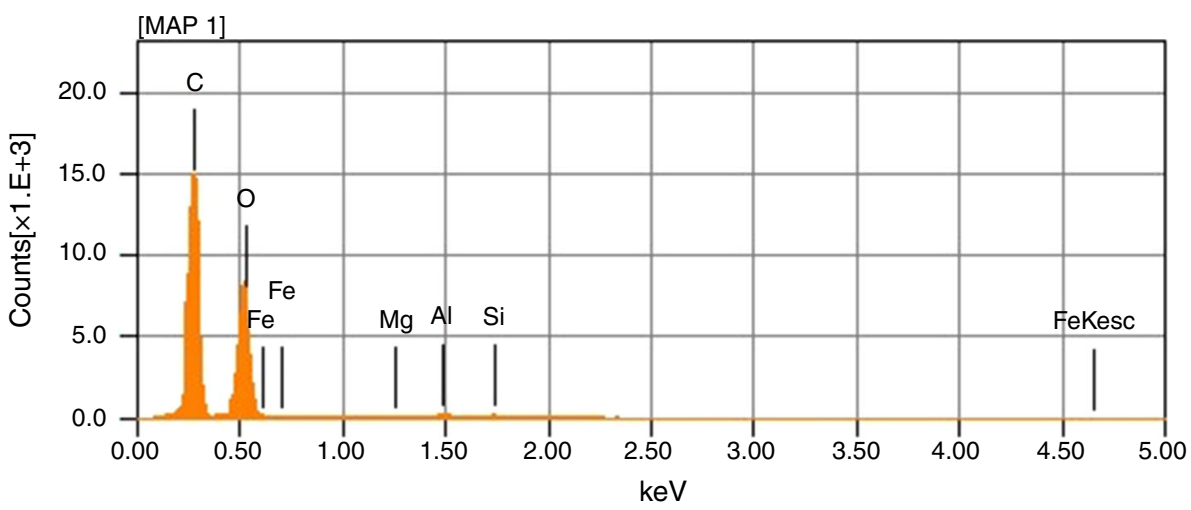

\section{Conclusions}

Thermal analysis allowed understanding the biomass behavior and his composition which indicates an appropriate biomass to bioenergy production due to higher contents of lignin, hemicellulose and cellulose noted at thermal decomposition. All models are in good accordance with the experimental data, while the KAS and OFW exhibited the best and similar results. A variance in the apparent activation energy and pre-exponential factors observed during thermal decomposition with isoconversional models implies that pyrolysis progresses rather through multi-step kinetics, showing the complexity and instability of this biomass. SEM analysis showed notable morphological and compositional differences among SCB and biochars. EDX showed carbon, oxygen, aluminum, silicon, magnesium and iron.

Acknowledgements The authors acknowledge the financial support provided by Brazilian Research Agencies: FAPESP, CNPq and CAPES.

\section{References}

1. Mandal A, Chakrabarty D. Isolation of nanocellulose from waste sugarcane bagasse (SCB) and its characterization. Carbohydr Polym (2011);86:1291-9. doi:10.1016/j.carbpol.2011.06.030.

2. Aboyade AO, Hugo TJ, Carrier M, Meyer EL, Stahl R, Knoetze JH et al. Non-isothermal kinetic analysis of the devolatilization of corn cobs and sugar cane bagasse in an inert atmosphere. Thermochim Acta. 2011;517:81-9. doi:10.1016/j.tca.2011.01.035.

3. Xu F, Sun JX, Liu CF, Sun R. Comparative study of alkali- and acidic organic solvent-soluble hemicellulosic polysaccharides from sugarcane bagasse. Carbohydr Res. 2006;341:253-61.

4. Lavarack BP, Griffin GJ, Rodman D. Measured kinetics of the acid-catalysed hydrolysis of sugar cane bagasse to produce xylose. Catal Today. 2000;63:257-65.

5. Bizzo WA, Lenço PC, Carvalho DJ, Veiga JPS. The generation of residual biomass during the production of bio-ethanol from sugarcane, its characterization and its use in energy production. Renew Sustain Energy Rev. 2014;29:589-603.
6. Da Silva ASA, Inoue H, Endo T, Yano S, Bon EPS. Milling pretreatment of sugarcane bagasse and straw for enzymatic hydrolysis and ethanol fermentation. Bioresour Technol. 2010;101:7402-9.

7. Binod P, Satyanagalakshmi K, Sindhu R, Janu KU, Sukumaran RK, Pandey A. Short duration microwave assisted pretreatment enhances the enzymatic saccharification and fermentable sugar yield from sugarcane bagasse. Renew Energy. 2012;37:109-16. doi:10.1016/j.renene.2011.06.007.

8. Saddawi A, Jones JM, Williams A, Wójtowicz MA. Kinetics of the thermal decomposition of biomass. Energy Fuels. 2010;24: 1274-82. doi:10.1021/ef900933k.

9. Heydari M, Rahman M, Gupta R. Kinetic study and thermal decomposition behavior of lignite coal. Int J Chem Eng. 2015; 2015:1-9.

10. Munir S, Daood SS, Nimmo W, Cunliffe AM, Gibbs BM. Thermal analysis and devolatilization kinetics of cotton stalk, sugar cane bagasse and shea meal under nitrogen and air atmospheres. Bioresour Technol. 2009;100:1413-8.

11. Guilherme AA, Dantas PVF, Santos ES, Fernandes FAN, Macedo GR. Evaluation of composition, characterization and enzymatic hydrolysis of pretreated sugar cane bagasse. Braz J Chem Eng. 2015;32:23-33.

12. Embrapa EB de PA. Procedures for Lignocellulosic Analysis. Brasil; 2010. p. 58. (in Portuguese).

13. Damartzis T, Vamvuka D, Sfakiotakis S, Zabaniotou A. Thermal degradation studies and kinetic modeling of cardoon (Cynara cardunculus) pyrolysis using thermogravimetric analysis (TGA). Bioresour Technol. 2011;102:6230-8. doi:10.1016/j.biortech. 2011.02.060.

14. Lopez-Velazquez MA, Santes V, Balmaseda J, Torres-Garcia E. Pyrolysis of orange waste: a thermo-kinetic study. J Anal Appl Pyrolysis. 2013;99:170-7. doi:10.1016/j.jaap.2012.09.016.

15. Vyazovkin S, Burnham AK, Criado JM, Pérez-maqueda LA, Popescu C, Sbirrazzuoli N. ICTAC kinetics committee recommendations for performing kinetic computations on thermal analysis data. Thermochim Acta. 2011;520:1-19. doi:10.1016/j. tca.2011.03.034.

16. Leroy V, Cancellieri D, Leoni E, Rossi J. Kinetic study of forest fuels by TGA: model-free kinetic approach for the prediction of phenomena. Thermochim Acta 2010;497:1-6.

17. Slopiecka K, Bartocci P, Fantozzi F. Thermogravimetric analysis and kinetic study of poplar wood pyrolysis. Appl Energy. 2012;97:491-7. doi:10.1016/j.apenergy.2011.12.056.

18. Yanfen L, Xiaoqian M. Thermogravimetric analysis of the cocombustion of coal and paper mill sludge. Appl Energy. 2010;87:3526-32. doi:10.1016/j.apenergy.2010.05.008. 
19. Xie Z, Ma X. The thermal behaviour of the co-combustion between paper sludge and rice straw. Bioresour Technol. 2013;146:611-8. doi:10.1016/j.biortech.2013.07.127.

20. Friedman HL. Kinetics of thermal degradation of char-forming plastics from thermogravimetry. Application to a phenolic plastic. J Polym Sci. 1964;6:183-195.

21. Păcurariu C, Lazău RI, Lazău I, Ianoş R, Tiţa B. Non-isothermal crystallization kinetics of some basaltic glass-ceramics containing $\mathrm{CaF}_{2}$ as nucleation agent. J Therm Anal Calorim. 2009;97:507-13.

22. Maia AAD, Morais LC. Kinetic parameters of red pepper waste as biomass to solid biofuel. Bioresour Technol. 2016;204:157-63. doi:10.1016/j.biortech.2015.12.055.
23. Kim YS, Kim YS, Kim SH. Investigation of thermodynamic parameters in the thermal decomposition of plastic wastewaste lube oil compounds. Environ Sci Technol. 2010;44: 5313-7.

24. $\mathrm{Xu} \mathrm{Y,} \mathrm{Chen} \mathrm{B.} \mathrm{Investigation} \mathrm{of} \mathrm{thermodynamic} \mathrm{parameters} \mathrm{in} \mathrm{the}$ pyrolysis conversion of biomass and manure to biochars using thermogravimetric analysis. Bioresour Technol. 2013;146:485-93. doi:10.1016/j.biortech.2013.07.086.

25. Burhenne L, Messmer J, Aicher T, Laborie M. The effect of the biomass components lignin, cellulose and hemicellulose on TGA and fixed bed pyrolysis. J Anal Appl Pyrolysis. 2013;101:177-84. doi:10.1016/j.jaap.2013.01.012. 